\title{
Constipation in children: The bird's eye view
}

\author{
Shaman Rajindrajith ${ }^{1}$, Niranga M Devanarayana ${ }^{2}$ \\ ${ }^{1}$ Department of Pediatrics, Faculty of Medicine, University of Colombo, Sri Lanka. \\ ${ }^{2}$ Department of Physiology, Faculty of Medicine, University of Kelaniya, Ragama, Sri Lanka.
}

Correspondence: Prof. Shaman Rajindrajith

e-mail: s.rajindrajith@pdt.cmb.ac.lk

(D) https://orcid.org/0000-0003-1379-5052

With a worldwide estimated prevalence of $9.5 \%$, constipation is considered as a significant health problem in children (1). However, epidemiological research in Asian countries has shown a much higher prevalence of up to $32 \%$ according to standard Rome III criteria (2). Similar studies in Africa show a prevalence of $27 \%$ in Nigerian school children (3). The highest prevalence noted in Sri Lankan children is $15.5 \%$ (4). Therefore, it is evident that a disease previously thought to be highly prevalent in affluent societies is becoming common among more impoverished societies showing a clear epidemiological shift. This changing epidemiological pattern indicates that childhood constipation is glooming to become a significant public health problem, especially in developing countries across the world.

Risk factors for childhood constipation are also found to be common in all communities. Psychological stress has been identified as an essential risk factor for developing constipation (5). Stressors such as home-related events (divorce of parents, severe illness in a family member) and school-related events (bullying, failing an exam) are known to predispose children to develop constipation (6). Similarly, emotional, physical, and sexual abuse are also identified as precipitating factors (7). With the changing socio-economic landscape and pressure for education, these factors are becoming more common predisposing many children to develop constipation. The fast-food industry is proliferating across the world and in Sri Lanka during the recent decade. Recent studies have shown a higher prevalence of consumption of junk food and sugary drink in children $(8,9)$.
Consumption of fast- food is a known predisposing factor for childhood constipation (10). Diet low in fibre is also associated with childhood constipation $(11,12)$. All these factors predispose current-day children to develop constipation, and therefore we are facing an uphill task in battling these worldwide trends shortly in view to prevent constipation.

Exact pathophysiological mechanisms of childhood constipation remain elusive and unclear. However, the majority believe it is a result of stool withholding after the painful passage of stools. When a child senses the necessity to pass stools, he / she tightens the gluteal muscles and resists the passage of stools to avoid the pain. This leads to an accumulation of faeces in the rectum. As the faecal mass gets larger, the rectal wall stretches to accommodate stools leading to dilatation of the rectum and loses the urge of defecation. When this mass finally passes through the anus, it leads to pain, which triggers more withholding behaviour. Once sets in, it is challenging to break the vicious cycle of painwithholding behaviour.

The effects of constipation have significant personal and public health repercussions. Children with constipation have a poor health-related quality of life in all dimensions, namely physical, social, school, and emotional (13). Youssef, et al., reported health-related quality of life of children with constipation was worse than children with severe organic gastrointestinal diseases such as inflammatory bowel disease (14). Furthermore, school absenteeism and poor school performances were also noted in children with constipation, indicating significant implications for their future as adults (15). Constipation is one of the leading 
gastro-enterological conditions for healthcare consultation in children. It had been shown that children and young adults with constipation sought more medical consultation, higher emergency room visits, and higher outpatient costs (16).

The criteria for the diagnosis of constipation have changed. Rome III criteria were used to diagnose constipation from 2006 to 2016 (17) . In 2016, they were replaced by the new Rome IV criteria. The significant change in Rome IV criteria was bringing down the duration of symptoms from 2 months to 1 month (18). This trend will also contribute to an increase in the prevalence in future epidemiological studies.

Constipation is a clinical diagnosis, and can easily be made using the existing Rome IV criteria (Box 1). A thorough history of bowel habits is mandatory to evaluate a child with constipation. It is also essential to explore the other symptoms associated with constipation, family, and social history to elicit stressful events and other social determinants. A dietary history is a mandatory component as a diet low in fibre and junk food consumption is known factors that precipitate symptoms of constipation $(10,12)$. The clinician should also inquire about the impact of constipation, such as its effects on quality of life and school performances, to explicitly understand the clinical picture. The physical examination should begin with an assessment of growth and dysmorphic features. The faltering of the growth curve is an early indication of hidden organic disease in some children. An abdominal examination may reveal the presence of faecal masses, indicating significant faecal retention. The perianal examination is a mandatory component of examining a child with constipation, which reveals faecal matter staining underwear indicating the presence of faecal incontinence and fissures explaining the pain, which leads to retentive behaviour. Digital examination of the rectum is rarely needed and should only be performed by an experienced clinician to detect faecal masses in the rectum and the sphincter tone (19). Examination of the lumbosacral spine may reveal features of spinal bifida occulta (haemangioma, a tuft of hair, asymmetry of the gluteal cleft) indicating defective innervation of the rectum and the sphincter complex.

Clinicians tend to order several common investigations when they encounter a child with constipation. Testing for hypothyroidism is still practised even though most children with hypothyroidism tend to have normal bowel habits (20), and constipation being a rare occurrence in hypothyroidism (21). Abdominal X-ray is another investigation that is commonly used to assess the degree of faecal loading. Several studies have shown the poor inter- and intra-observer reliability of X-rays in assessing the severity of constipation in children $(22,23)$. Most other investigations such as colonic transit studies, high resolution anorectal and colonic manometry, and defaecography are only needed in children with severe constipation refractory to standard medical care at least for more than three months.

Box 1: Definition of functional constipation according to Rome IV criteria

Must include at least 2 of the following occurring at least once per week for a minimum of 1 month with insufficient criteria for a diagnosis of irritable bowel syndrome:

1. Two or fewer defecations in the toilet per week in a child of a developmental age of at least 4 years

2. At least 1 episode of faecal incontinence per week

3. History of retentive posturing or excessive volitional stool retention

4. History of painful or hard bowel movements

5. Presence of a large faecal mass in the rectum

6. History of large diameter stools that can obstruct the toilet

After appropriate evaluation, the symptoms cannot be fully explained by another medical condition. 
Management of constipation in children is far beyond prescribing drugs. The main components include modifying lifestyle and diet, inculcating a toilet routine, judicious use of laxatives, use of biofeedback, and pelvic floor physiotherapy in children who do not respond to conventional medical interventions. When constipation is refractory to medical management, surgical interventions, and novel therapeutic strategies such as sacral nerve stimulation is indicated. Although commonly used in day to day clinical practice, some of these interventions has not been studied in randomized controlled trials. Therefore, most of the management strategies are not evidence-based and depend on the clinician's individual experiences.

As children with constipation are known to face stressful life events, careful consultation involving parents would help to alleviate problems at home. In addition, children need to be taught coping mechanisms. Avoidance of home and school-related punishments is another aspect that could minimize with adequate counseling of parents and teachers. Although diet low in fibre is a known precipitating factor, several studies have failed to show the benefit of a high fiber diet in treating constipation (24). The correct approach is not just to increase fibre in the diet but after the dietary assessment if the diet is low in fibre, to increase it to the recommended normal level (5 grams + the age of the child in years) (25). As most children have stool withholding behaviour, proper toilet training, and encouragement to use toilets with the urge of defaecation with a rewarding system is helpful in the management.

The first step in the pharmacological intervention is disimpaction of the rectum. Although many clinicians tend to use suppositories and enemas in Sri Lanka, most international guidelines recommend using high dose oral polyethylene glycol (1.5 $\mathrm{g} / \mathrm{kg} /$ day) or lactulose (4-6 ml $/ \mathrm{kg} /$ day) (25). Once disimpacted, it is imperative to prevent reimpaction by using maintenance therapy with osmotic laxatives (lactulose, polyethylene glycol), and stimulant laxatives (bisacodyl) in much lower dose compared to disimpaction. Other drugs such as magnesium sulfate, docusate sodium, and mineral oil have also been used during the maintenance phase. Novel drugs such as lubiprostone (a chloride channel activator specific to the gastrointestinal tract), linaclotide and plecanatide (guanylate cyclase $\mathrm{C}$ receptor activator), and prucalopride (5-HT receptor agonist) have not shown to be very useful in children during the maintenance phase. Pelvic floor physiotherapy consists of many facets, including training in the exercise of pelvic floor muscles, proper straining techniques, and increasing awareness of sensations. Novel data that are emerging show that this approach is more effective compared to standard medical management (26).

When the medical interventions fail, and symptoms of constipation persist, surgical interventions may be needed after proper evaluation of the colon with contrast studies, anorectal and colonic manometry. The interventions include botulinum toxin injection to anal sphincter complex, anal myectomy, antegrade continent enemas, colonic resection, and colostomies. However, currently, the determination of surgical interventions depends on the experience and the clinician's preference and therefore demands more evidence from novel research.

In summary, childhood constipation is a highly prevalent gastrointestinal disorder which amounts to a significant public health problem. The current evidence indicates the prevalence and risk factors are more commonly seen in developing countries and Asia and could contribute to draining the public health funds in the future unless the preventive measures are implemented soon. Constipation is a clinical diagnosis and can easily be made by using Rome IV criteria. Most of the currently available investigations are not helpful in the day-to-day management of children with constipation and only required in refractory constipation cases. Combination of both lifestyle modifications and medical management help to alleviate symptoms and improve the wellbeing of children. Surgical interventions are reserved for children with medically refractory constipation.

\section{References}

1. Koppen IJN, Vriesman MH, Saps M, Rajindrajith S, Shi X, van Etten-Jamaludin FS, et al. Prevalence of Functional Defecation Disorders in Children: A Systematic Review and Meta-Analysis. JPediatr, 2018; 198: 121-30, e6. 
2. Wu TC, Chen LK, Pan WH, Tang RB, Hwang SJ, Wu L, et al. Constipation in Taiwan elementary school students: a nationwide survey. J Chin Med Assoc, 2011; 74(2): 57-61.

3. Udoh EE, Rajindrajith S, Devanarayana NM, Benninga MA. Prevalence and risk factors for functional constipation in adolescent Nigerians. Arch Dis Child, 2017; 102(9): 841-4.

4. Rajindrajith S, Devanarayana NM, Adhikari C, Pannala W, Benninga MA. Constipation in children: an epidemiological study in Sri Lanka using Rome III criteria. Arch Dis Child, 2012;97(1): 43-5.

5. Philips EM, Peeters B, Teeuw AH, Leenders AGE, Boluyt $\mathrm{N}$, Brilleslijper-Kater SN, et al. Stressful life events in children with functional defecation disorders. $J$ Pediatr Gastroenterol Nutr, 2015; 61(4): 384-92.

6. Devanarayana NM, Rajindrajith S. Association between constipation and stressful life events in a cohort of Sri Lankan children and adolescents. J Trop Pediatr, 2010; 56(3): 144-8.

7. Rajindrajith S, Devanarayana NM, Lakmini C, Subasinghe V, de Silva DG, Benninga MA. Association between child maltreatment and constipation: a schoolbased survey using Rome III criteria. J Pediatr Gastroenterol Nutr, 2014; 58(4): 486-90.

8. Powell LM, Nguyen BT. Fast-food and full-service restaurant consumption among children and adolescents: effect on energy, beverage, and nutrient intake. JAMA Pediatr, 2013; 167(1): 14-20.

9. Rosenheck R. Fast food consumption and increased caloric intake: a systematic review of a trajectory towards weight gain and obesity risk. Obes Rev, 2008; 9(6): 535-47.

10. Tam YH, Li AM, So HK, Shit KY, Pang KK, Wong YS, et al. Socioenvironmental factors associated with constipation in Hong Kong children and Rome III criteria. J Pediatr Gastroenterol Nutr, 2012; 55(1): 56-61.

11. Morais MB, Vitolo MR, Aguirre AN, Fagundes-Neto U. Measurement of low dietary fiber intake as a risk factor for chronic constipation in children. $J$ Pediatr Gastroenterol Nutr. 1999; 29(2): 132-5.

12. Lee WT, Ip KS, Chan JS, Lui NW, Young BW. Increased prevalence of constipation in pre-school children is attributable to under-consumption of plant foods: A community-based study. $J$ Paediatr Child Health, 2008; 44(4): 170-5.
13. Vriesman MH, Rajindrajith S, Koppen IJN, van EttenJamaludin FS, van Dijk M, Devanarayana NM, et al. Quality of Life in Children with Functional Constipation: A Systematic Review and Meta-Analysis. J Pediatr, 2019; 214: $141-50$

14. Youssef NN, Langseder AL, Verga BJ, Mones RL, Rosh JR. Chronic childhood constipation is associated with impaired quality of life: a case-controlled study. J Pediatr Gastroenterol Nutr, 2005; 41(1): 56-60.

15. Olaru C, Diaconescu S, Trandafir L, Gimiga N, Olaru RA, Stefanescu G, et al. Chronic Functional Constipation and Encopresis in Children in Relationship with the Psychosocial Environment. Gastroenterology Research and Practice, 2016; 2016: 7828576.

16. Choung RS, Shah ND, Chitkara D, Branda ME, Van Tilburg MA, Whitehead WE, et al. Direct medical costs of constipation from childhood to early adulthood: a population-based birth cohort study. $J$ Pediatr Gastroenterol Nutr, 2011; 52(1): 47-54.

17. Rasquin A, Di Lorenzo C, Forbes D, Guiraldes E, Hyams JS, Staiano A, et al. Childhood functional gastrointestinal disorders: Child / adolescent. Gastroenterology, 2006; 130(5): 1527-37.

18. Hyams JS, Di Lorenzo C, Saps M, Shulman RJ, Staiano A, van Tilburg M. Functional Disorders: Children and Adolescents. Gastroenterology. 2016.

19. Constipation in chldren and young people: diagnosis and management [Internet]. Royal College of Obstetricians and Gylaecologists. 2010 [cited $26^{\text {th }}$ May 2020]. Available from: https://www.nice.org.uk/guidance/cg99/evidence/ full-guidance-pdf-245466253. (Accessed on September 2020).

20. Muller-Lissner SA, Kamm MA, Scarpignato C, Wald A. Myths and misconceptions about chronic constipation. Am J Gastroenterol, 2005; 100(1): 232-42.

21. Bennett WE, Jr., Heuckeroth RO. Hypothyroidism is a rare cause of isolated constipation. J Pediatr Gastroenterol Nutr, 2012; 54(2): 285-7.

22. Benninga MA, Tabbers MM, van Rijn RR. How to use a plain abdominal radiograph in children with functional defecation disorders. Arch Dis Child Educ Pract Ed, 2016; 101(4): 187-93. 
23. Berger MY, Tabbers MM, Kurver MJ, Boluyt N, Benninga MA. Value of abdominal radiography, colonic transit time, and rectal ultrasound scanning in the diagnosis of idiopathic constipation in children: a systematic review. JPediatr, 2012; 161(1): 44-50 e1-2.

24. Tappin D, Grzeda M, Joinson C, Heron J. Challenging the view that lack of fibre causes childhood constipation. Arch Dis Child, 2020; 105(9): 864-8.

25. Tabbers MM, DiLorenzo C, Berger MY, Faure C, Langendam MW, Nurko S, et al. Evaluation and treatment of functional constipation in infants and children: evidence-based recommendations from ESPGHAN and NASPGHAN. J Pediatr Gastroenterol Nutr, 2014; 58(2): 258-74.
26. van Engelenburg-van Lonkhuyzen ML, Bols EM, Benninga MA, Verwijs WA, de Bie RA. Effectiveness of Pelvic Physiotherapy in Children With Functional Constipation Compared With Standard Medical Care. Gastroenterology, 2017; 152(1): 82-91. 